\title{
From expert student to novice professional: Higher education and sense of self in the creative and performing arts
}

\author{
Anna Reid ${ }^{1}$, Jennifer Rowley ${ }^{1}$ and Dawn Bennett ${ }^{2}$ \\ ${ }^{1}$ Sydney Conservatorium of Music, University of Sydney \\ ${ }^{2}$ Curtin University, School of Education
}

The employability of graduates is of concern across further and higher education, but it is particularly problematic in the Creative and Performing Arts disciplines. Understanding the journey to work for arts graduates requires collaborative action from multiple agencies, particularly the collection and reporting of nuanced statistics on higher education graduate outcomes and empirical investigations of graduate work and employability. This paper reports on a study of Australian creative workers who described how their experiences of work inform their sense of 'being' and 'becoming'. Two models are discussed in relation to the transition from student to professional worker. The first model explores how the self-determination of an individual's motivation influences the success of the transition. The second model poses a multidisciplinary view of student engagement and provides a lens to the transformative processes for developing one's sense of being through tacit knowledge and active engagement in professional self. The article exposes models of selfhood that might enhance our understanding of higher education students' sense of becoming as well as how these models might be applied within the higher education context.

Keywords: tertiary education; employability, scholarship of teaching and learning, identity, career, arts, music, motivation, transformation 


\section{Introduction}

Making the transition from student to professional is a complex process. For some, including graduates from the creative and performing arts (referred to here as 'arts graduates'), the complexity includes learning to navigate careers that demand an entrepreneurial approach from the point of graduation, and even before. The reportedly poor employability expectations of arts students relate to community and student perceptions that degrees in the arts do not lead to a 'real job'; however, higher education has rarely invested the time needed to understand the personal and environmental characteristics of career, learning and graduate transition for arts graduates.

The study reported here concerns 182 Australian graduates working in the creative and performing arts sector who describe how their experiences of work inform their sense of 'being' and 'becoming'. The paper exposes models of selfhood that might enhance our understanding of higher education students' sense of becoming as well as how these models might be applied within the higher education context. Importantly, we suggest that an epistemological understanding of creative and performing artists will enable appropriate preparation in higher education where the emphasis is currently on arts practice rather than identity. We begin by describing the background and theoretical framework for the study, and then present the approach. The findings and discussion are structured around the seven key identity traits that emerged from the data.

\section{Background}

Higher education graduates from the creative and performing arts encounter complex and precarious working lives that feature multiple transitions, complex employment arrangements and do-it-yourself career management. Australia's graduate destinations data report these graduates (known here as creative workers) as having the poorest 
graduate employment outcomes of all 40 broad higher education disciplines (Graduate Careers Council of Australia 2015). However, when all work is considered—employed and self-employed roles and both part-time and full time work- the employment outcomes of all higher education students emerge as relatively similar (Bennett et al. 2015). Australia is also a complex environment for creative work. There are only five major cities with populations greater than $1,000,000$ and they are located many thousands of kilometres from each other. The majority of Australia's cities contain between 10,000 to 100,000 people (Geonames, 2019). The consequence of this is that creative work is largely localised with infrequent opportunity for people to move efficiently between them. This concentrates creative work into particular locations where the community has determined that funding and supporting creative workers is important. For small towns a cultural and creative activity can support the economic and social survival of the population. Such was the case with the Kalbarri 'Zest Festival' that ran from 2013-2016 (Zestfest). Highly educated creative and performing artists enter a nebulous work environment where the quality of their arts practice developed at university simply may not be the thing that enables them to survive economically or artistically.

The work of arts graduates is characterised by non-linear career paths featuring interruptions, setbacks, highlights and downtime. Many of Australia’s 20,000 arts graduates each year aspire to engage in work related to their creative discipline. In reality, this is rarely the outcome. For example, Cunningham and Higgs (2010) found that $65.5 \%$ of dancers or choreographers and $40.5 \%$ of musicians, singers or composers work mostly outside the creative industries. Research also indicates that creative workers encounter both 'good and bad' work (Fitzgerald, Rainnie, and Bennett 2011), 
typically with small firms and on an ad-hoc basis. Multiple concurrent roles are increasingly common across the labour market (Sabelis 2010), and in the creative workforce they can persist — together with precarity—-throughout the career life cycle (Bennett et al. 2014).

The nature of creative work highlights the need for students to develop the capacity to create and manage a small business, the resilience to sustain intermittent and complex work, the social awareness and creativity needed to generate opportunities within and beyond the arts sector, and acceptance that a sustainable career is likely to involve work unrelated to the arts. Arts graduates commonly report that they do not have these skills and capacities on graduation (Bridgstock 2012; Comunian, Gilmore, and Jacobi 2015; Throsby and Zednik 2010). It follows that the challenge for educators is to understand what graduate work might look like and how students might prepare for it.

Work such as that described above presents challenges to workers' self and identity (Alvesson et al. 2008). Hence, students' developing sense of self emerges as a core component of higher education in the creative and performing arts. Despite the increasing prevalence of such work, however, little attention has been paid to graduates who encounter discontinuous work identities, or how they otherwise deviate from socially scripted or highly institutionalised trajectories (Ashforth 2001).

\section{Theoretical framework}

Self-determination theory (SDT) is a broad theory of motivation that examines the nature and sources of motivational quality. SDT focuses on types of motivationcontrolled, autonomous and a-motivation - as predictors of performance, relatedness 
and wellbeing (Ryan and Deci 2000). In this context, a-motivation is a lack of motivation or general ambivalence towards an activity - in this case - artistic work, characterised by a lack of perceived competence and/or perceived value in the activity or its outcomes.

Higher levels of self-determination are associated with an increased likelihood of successful transformation through a process of external and internal regulation. In the context of higher education, this can be seen in the form of students who are intrinsically motivated; they need less external regulation and they tend to transform from student to professional with fewer incidents. For these students, 'sense of self' is related to, and enhanced by, practical action and activity. In contrast, students who are not intrinsically motivated need additional extrinsic motivation and tend to struggle relative to their peers when transitioning to the workforce. The third category concerns students who are a-motivational in that they are not influenced by the intrinsic or the extrinsic.

The 'sense of self' model (Rowley and Munday 2014) argues that many students at the commencement of their academic study are extrinsically motivated. According to Ryan and Deci (2000), extrinsic motivation is something that comes from the external social world rather than from within. Students are choosing to study a discipline that is of interest to them and in which they feel they have skill and even expertise (which is often the case with those entering tertiary music study) and much of their early years of study is influenced by pedagogical approaches and discipline knowledge. In their final year, students' motivation has become intrinsic as they move closer to professional practice and their view of themselves as an ideal-self. In this sense, the experiences that students have had during their studies have moved from being stimulated through the 
external environment, to one where their ideas are now reflective and hence internally oriented. Later in this article we describe this move at an epistemological level as 'being and transforming'.

The first model proposed in this article is based on Ryan and Deci's (2000) SelfDetermination Theory and Lawrence's (2006) Self-Concept. The model seeks to encapsulate the strength of reflexive practice on students' thinking about their 'ideal self' as a practitioner.

In summary, SDT impacts on the transformation of the individual via the following aspects:

(1) The tendency towards personal growth and a more unified sense of self is supported through the fulfilment of the basic psychological needs of competence, relatedness, and autonomy.

(2) Behaviour is more enjoyable and contributes more to personal wellbeing when motivation is internalised and more closely aligned with the self.

A different way of viewing the problem is seen in the 'Relational and Multi Dimensional Framework of Student Engagement' model developed by Solomonides (2013). The model is a melange of various researchers' work that has investigated the sense of being and becoming of graduates to professionals. The model claims that knowledge and becoming are not clearly dependent on each other. It emphasises a conception of knowledge rather than learning and posits that there is a need for students to re-orientate their focus to integrate knowing, learning, acting and being. The model acknowledges that students work within their level of experience, and cites Solomonides and Reid (2009), who observed that the presence of identity as 
simultaneously singular and multiple is apparent in musicians - both practicing and aspiring. This is, in effect, evidence that a student's sense of being and sense of transformation are vital to the building of identity and engagement for future career building and considers the value of professional knowledge, discipline knowledge and engagement (Rowley, Bennett, and Reid 2017).

Hulme and Hughes $(2006,193)$ recommend "bringing the self" into discussions of professional practice and using "patchwork text" to represent professional development. The patchwork refers to texts that are linked to illustrate a theme or set of perspectives, which a learning tool such as an ePortfolio uses in "fashioning or fabricating their own narrative of their personal and professional development - often referred to as 'my story' $(2006,196)$ when investigating the transformation of student to worker" (Munday, Rowley, and Polly 2017). So here we find the benefit to learners who engage in the development of a narrative or 'story' - which has been shown to assist them in a process of transformation. This aligns with Gwozdek, Springfield and Kerschbaum's (2013) claim that self-assessment through self-reflection can be characterised by self-awareness of personal value, responsibility, and contribution.

With regard to the 'sense of self' model (Rowley and Munday 2014), students are extrinsically motivated at the beginning of their tertiary study and as they move through their degree the image of their future 'self' aligns with their self-concept and assists with enhancing their self-image. This in turn guides them away from their current self and toward the future self, indicating a transformation in both image and motivation that is becoming intrinsic as the reality of professional ideal 'professional' self becomes more visible. 
These models of motivation and transformation provide different lenses to understand the experience of professional creative workers. Investigating creative and performing arts students' understanding of self and their profession, for example, would provide information of their expectations of professional work. In the study we present below, we look at creative workers' experiences and instead use this information to look in retrospect at their education. As educators we would hope to use this information to transform curriculum and provide situations in which students can better come to understand their artistic thinking and practice in relation to their potential work.

\section{Approach}

We have previously related creative workers' construction of broad professional identities with their perception of the alignment between self and creative work. We first explored this in a creative context, drawing on the framework of 'possible selves' (Markus and Nurius 1986) to encourage discussion of both positive and negative images of the self (Bennett, Reid, and Rowley, 2017). We then employed Ashforth et al.'s (2008) definition of identity as 'self-referential' to highlight the fluidity of the artist identity across the career lifespan (Reid, Bennett, and Petocz, 2016). Here, we examine the 'stories' told by creative workers to answer three research questions:

(1) How do models of selfhood help us understand sense of becoming among higher education students?

(2) How do creative workers' experiences of work inform their sense of becoming? (6 themes); and

(3) How do creative workers' experiences of work inform how models of selfhood might be applied within the higher education context? 
Once ethical approvals were obtained, potential participants were recruited through Western Australian creative industries networks using respondent-driven sampling with multiple initial sources. The 182 survey respondents represented a broad spectrum of creative occupations and employment types. They were aged from $18-80 ; 60 \%$ were female.

The lengthy survey asked 48 closed and open questions with some repeated items for the purposes of triangulation. Respondents described their main and secondary occupations, income, and allocation of time. They also detailed the locations of their work, their motivation and identity, and their learning. Two questions, written below, prompted the respondents to reflect on their careers.

Q32.1 Can you identify an age, 'moment' or period of time when your career aspirations shifted?

Q48 This research will gather stories about the impact and value of the arts within the community, and about the wide-ranging skills, knowledge and activities of artists. If you have a story to share we would love to read it.

An interesting approach to collecting information about people's experience of working in creative areas was to ask them to tell stories about their experience (Bruner 1986). The resulting narratives ranged in length from three or four paragraphs (the usual) to eight pages (the extreme), and form the basis of the material analysed for this article.

The written stories allowed us to adopt a phenomenological perspective. Each response was considered within a narrative framework that positions people's stories as a component of their personal social spheres (Connelly and Clandinin 1990) expressed in words, phrases and images. Following Dillon $(2011,213)$, our narrative inquiry 
looked for "processes of self-making" by exploring personal meanings within, and commonalities and differences between experiences. Drawing on the model presented earlier, seven related aspects of identity were explored in the data. These are described at Table 1.

Table 1: Aspects of identity

\begin{tabular}{ll}
\hline Aspects of identity & Description \\
\hline Intrinsic & $\begin{array}{l}\text { Activities seen as personally } \\
\text { meaningful, aligned with sense } \\
\text { of being }\end{array}$ \\
\hline Extrinsic & $\begin{array}{l}\text { Activities driven by external } \\
\text { rewards such as remuneration } \\
\text { and public accolade }\end{array}$ \\
\hline A-motivation & $\begin{array}{l}\text { Activities characterised by a lack } \\
\text { of perceived competence and/or }\end{array}$ \\
& value \\
\hline Study & $\begin{array}{l}\text { People's experience of formal } \\
\text { and informal education }\end{array}$ \\
\hline Sense of becoming/being & A person's understanding of self \\
\hline Transformation & Change resulting from \\
& experience, including learning \\
\hline Understanding the context & $\begin{array}{l}\text { Understanding the context of life } \\
\text { and work }\end{array}$ \\
\hline
\end{tabular}

The text was coded using NVivo10, enabling exploration of relationships between individual key words, whole paragraphs and ideas, the frequency of ideas within any text, and the range of ideas within individual transcripts or across the whole.

The narrative structures of each story were somewhat different, with some being recounts of experiences, explanations of situations, reflective statements, and complete short stories. In the following discussion we examine the responses made to the two reflective survey questions. These questions prompted respondent narratives created 
without the discursive element of an interview, affording us a rare glimpse of the complex processes by which respondents made sense of their lives and work.

Moreover, as Corden and Sainsbury $(2006,12)$ suggest, "what people actually said and their choice of words was sometimes especially useful in illuminating what went on intimate relationships" with self, others and with work. For this reason, we devote considerable space to these voices through the provision of extended quotes in order for their meaning to come out as direct glimpses of lived experience. For each of the seven aspects of identity we present several quotations from different participants that illustrate the core elements of each aspect of identity.

\section{Findings and discussion}

Based on Reid and Solomonides' (2007) previous research with art and design students, we note that 'being and transformation' are aspects of identity that are core to persons. As such, understanding of personal development and career directions is enabled as a result of implementing and assessing learning in a reflexive way, having engaged in longitudinal thinking that aligns learning with future practice (Rowley and Bennett 2016).

\section{The aspect of being}

The aspect of 'being' relates a person's understanding of self as creative artist - it is an epistemological aspect that is central to their perception of self. Reid, Bennett and Petocz (2016) observe that persons were convinced of their artistic identity if they used short phrases (such as "I am an artist") when describing themselves. If the phrase were longer (such as "I am an artist, but I also work as a teacher") then their artistic identity was somewhat more apologetic. 
When I was 8 , I wanted to be a photographer. When I was 16 , I wanted to be a photographer. When I was 21 , I wanted to be a photographer. When I was 25 , I finally listened to myself and became a photographer.

The continually emerging professional and artistic field requires adaptability: skills of projecting the self into previously unknown settings. The quotes below shows this adaptability as the artist moves through common doubts regarding the choice of artistic work, personal doubts as to the meaning and utility of the career choice, and an internal resolution between self and the external situation.

Everyone in the arts always goes through the [question of] "Should I really be doing this? Am I in the right career? I'm always broke, should I give up?" But you should never give up. Yes, it is difficult, but it is our passion and you can't turn your back on that burning desire - to want to do what you really love with your life. The ultimate goal of wanting to be an actor doesn't shift: you just have to juggle other things around it to still be able to support yourself.

It took me many years to understand how vital is music to me and that literally I cannot live without being involved with it. So now that it is very clear to me, I feel good, enthusiastic and confident under my own skin and I see my original career aspirations smiling at me again :-).

When does someone realise that their passion is their primary motivation for success? For our participants, articulating who they are as creative workers and creative people seems to validate and deepen their understanding of career focus and goals. The following two examples come from an emerging artist and an established singer.

I'm 19 this year so there isn't going to be a very large story that comes with my experience; however, by the end of reading this you may think, "Small but deadly"! Being very lucky, I have always wanted to become an artist - ever since from the age of 3 .

Being creative, to me, is a part of being human. My belief is that every individual has the 
potential to create something of value that produces a positive reaction in its audience. It is wonderful to look at something that someone has made and be amazed by their talent or to hear someone sing, and be brought to tears at the sound. Good art makes me feel good!

One of the student participants articulated the applicability of her interpersonal skills to her work in music: "I quickly caught on ... being stage manager came easily to me as I am good at communicating with people and getting the job done". Applying this to her internship, she experienced unanticipated benefits.

I have learnt that the nicer you are to people and the more respect you show them, the more you will end up with a good result. ... [The company] was so happy with my attitude and help that they let me participate in a master class with renowned Australian opera singer [hidden]. This was so valuable to me as a young artist...

The same student later realised that her outgoing "personality and talent" were also crucial to building professional networks.

I have met the company and now they already know me and my personality and talent, so I believe I have a 'foot in the door' so to speak.

I saw the high standard of singing present in young artists and the futures they have ahead of them. This reinforces that I definitely need to keep on improving vocally and continue to work on my stagecraft skills in order to succeed in this highly competitive industry.

These quotes emphasise the personal determinations of these creative workers that they are creative artists at an epistemological level.

\section{Study}

Boud, Keogh and Walker's model of phases and prompts (1985) adopts the basic assumption that learning is always grounded in prior experience and that any attempt to 
promote new learning must take account of that experience. As such, all learning builds on existing perceptions and frameworks of understanding and links must be made between what is new and what already exists if learners are to make sense of what is happening to them.

The applicability of non-performance courses also became evident, as seen below in the comments of a vocal student.

After watching many hours [of] rehearsals, I became very aware of those who had a lot of musical knowledge and those who found it a lot harder. ... This could affect whether the artist will be hired again ... Thus, I learnt that all those aural, harmony and choir courses I have taken at the conservatorium will be very helpful in becoming a good musician in the real world of opera.

Seen above, new learning included awareness of the high standards required to be competitive as a singer. However, learners also bring to each event their personal foundation of experience: their prior learning and the combined influence of their previous experiences. Past experiences profoundly affect perceptions of what does and does not count as important; they act to sensitise us to some features of our world and blind us to others, and they shape the intent which in turn guides our priorities.

Boud, Keogh and Walker's (1985) second assumption is that the process of learning from experience is necessarily an active one. Much of the benefit of participating in any event derives from how we can shape our participation to suit our goals. One student was based at a local radio station and she came to understand that the sustainability of any venture, whether a concert series or radio show, is dependent on sustaining an audience. This led her to consider the broader demographics of the listening audience. Reflecting that the radio station was local rather than national, she 
realised:

This is the game changer really, for in this difference we can find our niche and really flourish.

She continued:

[National classical radio announcers] are usually middle-aged with a cultured accent with English tones injected into their use of language changing the Australian pronunciation of words such as 'dance' from 'dairnce' to 'daahnce' ... but we also have a chance to be different. The station is already placing emphasis on local events and community involvement by volunteers. I think we should aid this community feel with younger announcers and paired programs to reach a wider demographic.

By the end of the internship, the student had devised a student-led radio show, recommending:

... a more structured form of this internship - to the end that they [the radio station] could host a show aimed at university students ... it would be with me, and a con [conservatorium] student with knowledge in classical music. It would be fun, with great music and banter.

In our research, the key identity trait labelled 'study' signalled a means of legitimising what people were doing; it also afforded new ways of thinking. Participants often described the context in detail when writing about their experiences. The three participants quoted below reveal diversity in how people came to study in the creative arts.

When I graduated (during the middle of the financial crisis), I could not find a job anywhere ... so I decided to go back to university and study something creative this time. I did multimedia design and discovered that I had a talent for all sorts of different things from web design to animation and graphic design, and realised that I'd actually really enjoy 
working as a professional designer or advertiser. My current career ambition is to make a name for myself in the design industry by composing soundtracks, songs and jingles, although any other area of design would also be fun. I have great academic results and a portfolio, so hopefully I'll be able to find work.

When I was awarded a $\mathrm{PhD}$ scholarship at age 24, writing went from being a hobby to being my full-time occupation; this allowed me to take my writing more seriously.

I became a courier driver before buying a small franchise business. I still had the urge to create art and I phoned [hidden] University to ask about courses. The next week, I met one of the lecturers and signed up for a full-time BA course. That was 2008. I sold my business 6 months ago and am now in my 4th (Honours) year.

The participants in our study described multiple pathways to their formal creative arts studies. Their decisions were not limited to any particular life stage and many participants were simultaneously both students and workers. Many participants combined work and study. Work that was unskilled or temporary, and work related to a first career outside the arts, was often unrelated or tangential to the participants' creative arts discipline.

\section{Transformation}

Transformation is the other component of this core identity as it pertains to change that results from experience, including learning. Transformation seems most readily to have a catalyst in formal and informal education.

Undertaking a master's degree abroad changed how I thought about art and matured me [as a person].

Although the money was very good and welcomed, it [the stage show] was the worse month of my life because I had to sing a disgusting repertoire every night, for 30 nights! It was a nightmare. I felt somehow that I was prostituting my art, my music. The feeling was 
so bad that after that month, I decided to stop singing indefinitely. It was my first big career crisis.

I have very recently learnt new skills and techniques from young composers as part of the [orchestra's] composers project, and they [the musicians] have learnt new things from us in a very demanding and awesome program. We are all moving forward!

My own company works with the oral histories of seniors and I have written \& directed many plays based on interviews on various topics e.g. WWII, the Depression years of the 1930's, immigrants after WWII, and the histories of various suburbs of [city hidden]. The impact of this work on the community is significant - it affirms the value of seniors and brings people together within communities, acknowledging shared heritage and the importance of sharing reminiscences and thereby evaluating our lives and making decisions for the future. Live performance is a very powerful way of reinforcing all the above and the process is moving, joyous, empowering and uplifting.

I find community theatre is a huge help to many people. It allows them to get themselves out into the local society, meet new people, learn new skills and most of all have fun!

For one student, some of the most valuable learning within an internship setting occurred during informal conversations over dinner, highlighting the importance of informal social networks.

It's amazing how much you can learn about the music industry from a casual dinner conversation. ... It was an invaluable experience to talk to the staff about their journey as musicians ... We all gained some valuable insight into what we can do after we finish studying ... This was by far my favourite learning experience and not one I expected to have. As a performance major, our studies are very focused on performing and we are very contained as part of the university experience. We don't get much outside perspective and it was great to have this.

The student immediately transferred some of this learning to his own practice:

I have integrated some of the string tutor's teaching technique into my own teaching using 
anecdotes that are particularly useful for describing string technique.

Other learning was transformative because some of the hidden aspects of music work became visible.

Each day, problems would be brought to the admin staff's attention and they would come up with a solution to fix it. As performers, we are spoilt! We forget that there is someone who puts out the chairs every day, or finds extra copies of the music.

Exposure to aspects of a musician's practice beyond performance sparked new interests in many of the student participants. For some students, this resulted in changes to their study plans.

... it became apparent that although I have some teaching experience, some structured education in the science of teaching would be highly beneficial. I've enrolled in [the subject] String Pedagogy for next year and I'm looking forward to improving my teaching skills. I was also exposed to the administration side of music. I am considering doing the Music Management unit of study offered at the Conservatorium, to learn more about this as I found it interesting to see how much went on behind the scenes.

Not surprisingly, student participants' re-assessment of their knowledge and skills in relation to potential career pathways and learning opportunities contributed positively to their career thinking and their self-determination.

\section{Context}

Understanding the 'context' in which arts practice occurs from the participants' perspective allows us to understand the complex environment in which creative artists work. For some creative artists the context also provides the motivation to create. This extrinsic motivation can include remuneration, public accolade, or CV-building opportunities. As seen in the following quotes, employability in the creative arts is also 
nebulous in that creative artists' work can be subject to serendipity, may rely on community cultural events, and is often poorly paid or unpaid. Consequently, creative artists can only survive in these contexts if they have a strong sense of 'being' a creative artist. In this way they are able to be self-motivated and resilient in the face of adverse environments, open to oblique opportunities, and they often have a longer term goal of artistic career sustainability.

I advocated that artists need to work alongside other business professionals because they have specific and needed [valued] skills to contribute to the work we all face in terms of an environmentally healthy and sustainable future.

I suspect that I got into painting when I was in my early teens, as a method of having books with naked women lying around. I painted fairly seriously for about ten years and still do occasionally, and I have always written poetry and short stories. In the early seventies I started, at the behest of my then-wife, to take some roles in plays at New Theatre, in [city hidden]. Professional roles followed, and I earned a pretty good living as an actor for a few years. That ended when I became a teacher, but the writing continued.

Career-related doubt is particularly pertinent in discussions relating to technology. As seen in the following story, the arts and technology intersect so quickly that there is no single profession; rather, graduates encounter diverse and often disparate opportunities.

Became a mother in 1988 and continued as a freelance graphic designer/illustrator/storyboard artist. The impact of computer technology became evident in this industry - one in which I wasn't in a position to grow with at that time. I returned to secretarial skills as a medical secretary for a few years. The creative urge was too strong, and with an interest in gardens I started to design residential gardens. It was during this time that I finally decided to devote [myself] full time to making art - to pursue painting.

I'm not optimistic about being able to fulfil my childhood dream of being a singer/songwriter, at least not as long as I live in Australia. I don't think my personality 
matches Australian culture well. Instead, it's my hope that I'll be able to find work at a design or advertising company and perhaps find opportunities to compose music for a living that way, along with other creative work.

We contend that students need to be encouraged to explore such possible future 'selves' in multiple labour market contexts. This might be facilitated through formal and informal experiential learning, including reflection on study before and concurrent with higher education. We see this as a central aspect of the journey one takes toward career readiness and employability (see also Lebler, 2014). We also see such exploration ás central to the realisation of social citizenship through the arts: to developing an understanding of the arts as an intangible cultural heritage and social change agent (Petocz, Reid, \& Bennett, 2014), as seen in the account below.

Festivals bring people from wide communities together. I work for an event company and the hard work, sweat and tears put into that is a massive pay off, when the community respond by supporting and participating - whether free or paid ... We all depend on each other to make these festivals a success. It's important that we keep the music alive and real in all walks of life. We start with communities, big or small. Participation is key and sometimes overlooked. If we had more support from the local government we could get younger generations/older generations of Australians to come together. Imagine the possibilities.

The obvious implication for higher education is the need for students to experience work-related and community activities. Within these contexts, students develop not only the knowledge and capabilities to equip themselves for the future, but the interests which fuel self-determination .

\section{Extrinsic}

The Australia Council for the Arts estimated that in 2016, 15,400 musicians (excluding 
composers) were working in Australia; $80 \%$ of these musicians identified as freelance or self-employed. The study reported that musicians undertake a wide range of both arts and non-arts activities through which they develop the skills and capacities with which to adapt to changing environments.

Creative and performing arts students are often associated with careers described as a 'portfolio career' because they work in multiple roles which can be part-time or freelance and both paid and unpaid. Examples of the portfolio careers described by participants included working in music/art stores or retail stores not associated with their discipline, 'gigging', teaching privately in a studio, and work in schools such as running art classes or music ensembles.

The first quotation in this section provides a view of the work situation and the difficulty that situation provides for the artist where the form of the art does not seem to be appreciated. The second quotation also speaks to the work situation and emphasises the effect of the art on others. Each of these external situations becomes a catalyst for artistic response.

The field of caricaturing in [my city] is extremely niched and under-valued, and often a solitary existence. This contrasts to other bigger cities such as Melbourne where the art of caricature is burgeoning. Support for caricaturists is almost non-existent - the Australian Cartoonists Association is the best support for this but unfortunately focuses on cartoonists and seems to somewhat neglect caricature as an artform. There is also no training or recognition for the art of caricature in general in Australia.

My work gives people pleasure, immense pleasure if the two reader emails a day are anything to go by. That is not to be sneezed at in a world full of war, terrorism, famines, poverty, etc. I'm particularly proud that I give older people (an undervalued group) pleasure. I've had a lot of emails from widowed people who say my books help fill their lonely hours and also from carers (e.g. of Alzheimer patients) who say the same. 
Individual perceptions of success are informed by people's intrinsic work/life satisfaction and in the expectations of others (extrinsic) as they strive to meet personal and professional needs. Passion, or career calling, is a key element of both motivation and success; yet passion, artistic authenticity and practical concerns such as income can be incompatible. Portfolio work features networked forms of employment in which market visibility, networks, innovation and communication are essential aspects of sustainability. Much of musicians' work is characterised by short-term or project-based contracts or affiliations. Indeed, Bennett and Hennekam (2018) found that many musicians encounter such insecure work across the career lifespan and that they compensate with the development of new skills, the inclusion of unrelated work and, particularly in late career, the transfer of their existing skills into new contexts. In a sense, then, the development of employability among aspiring musicians relies on their acceptance of the need for persistent employability work and the adoption of a broad career purview.

\section{Intrinsic}

Intrinsic motivation describes a circumstance where an activity is seen as personally meaningful and aligns with a person's sense of being; it can also support transformational thinking.

My career aspirations haven't shifted at all, but it is always a challenge to keep the integrity of it [when] having to survive as an artist in the commercial world. I am always aware of it. From time to time, I realise I am getting away from my aspirations, so I know I have to stop to correct the "direction of my boat" again.

I have been working towards my first solo exhibition which hopefully will happen in September in an artist-run space currently undergoing a refurbishment. Whatever the outcome of the solo show, I will keep pursuing painting.

I get so much pleasure in hearing from people to whom I have performed that they had never had much interest in poetry, but that now they were converts! :o) Yay! That's what I strive for and why I keep plugging on. I feel like a lone disciple in a sea of unbelievers 
most of the time when I write at home, but once I get out there, I can see that my humble efforts are actually impacting in some way on those who stop to listen.

My aspiration and dreams are to hold exhibitions in Australia's top galleries and perhaps one day become an internationally renowned artist. Whatever it takes, I wish for my art to help the world's people and the environment we live in.

The publishing industry in Australia is, sadly, more interested in "sameness", in the safety of the well-trodden path. To get something different out there is rather difficult. Yet, it will not stop me. I will keep writing.

I would like to work as a full time professional artist, though it seems an impossible dream. Never-the-less I will not give up.

Relating their theory and practice, one student commented:

Up to the point of the [employability] workshop, I had had very little experience in the way of real situations in which I could apply what I have been learning at the Con.

\section{A-motivation}

A-motivation in this study comprised activities which were characterised by a perceived lack of competence and/or a perceived lack of value to the creative artists' lives and works. For some participants, for example, family was experienced as an a-motivation, where for others it was a core intrinsic motivation. None of these aspects can be seen in isolation; rather, they should be considered in concert as a unified part of the creative artist's experience.

The short quotations to follow show that each person has a story about their experience and that the stories align with their sense of self. We include a word of caution: the written stories are simply moments in time and should not be taken to 
represent the entirety of a person's experience; rather, we use the words to demonstrate the key characteristics of each aspect.

I just wish I had more confidence (as you will have noticed throughout the questionnaire!), and I feel a large part of this lack stems from the deficit of support of the arts in the wider community. There is a need for it out there, but our world revolves around the big bucks, and little folk like me who try to make a difference are mere plankton in the ocean compared to the fat cat sharks who drive the economy.

Graphic Designers are often employed as 'designers', yet managers and bosses steal good ideas, demand fast pace and high turnover and make you do a lot of roles out of your job [description]. Being an artist is a lifestyle - you cannot be creative in the demands and society we live in. Only with good sleep, exercise and passion can an artist create work, yet this is luxury only the rich can afford.

The creative workers' voices, presented as quotations for key aspects of identity and practice, illustrate a diverse range of life experiences and expectations. Once in the workforce an artistic career appears to be one where great resilience is required. It seems that creative workers need a strong inner core of belief in their art-making and that they need to be able to see how they can use external situations to transform their art-making into a society changing practice. Where creative workers seem a-motivated, it is not their core identity that contributes to this but rather the external environment factors that have hindered their personality development and where their making is not appreciated (or remunerated well).

\section{Concluding comments}

Looking back from a career to higher education, we observe that higher education tends to focus more on the skills of making with very little preparation for the business and entrepreneurial components of work. We can also see that those creative workers who 
have a strong 'sense of being', or a very clear engagement with their artist identity, are also those who are most resilient to the external working environment. We wonder then if more time in higher education could be spent on students' development of their artist identity and to the design and management of their future careers.

The research reported here suggests that creative workers' desire for a positive artistic career blurs the tensions between their artistic identity and their transformation through learning. Learner identity seems to act as a connector for making shifts in thinking from student to self-directed, autonomous arts professional in a rapidly changing professional landscape.

The data provide some interesting considerations for higher arts education. As educators, we want our students to appreciate the importance of both classroom and field educational experiences and learn that there is nothing more practical than a good theory (Vansteenkiste and Sheldon 2006). It is expected, therefore, that academics work to create opportunities for their students to engage in learning that relates to real world experiences and provides authentic learning environments to include rich learning that engages higher-order thinking skills. Students adapt to new pedagogic practice quickly when it is integrated purposively into curriculum and when it highlights the real-world experiences of an individual, personal, and professional nature. With the benefit of these experiences, students moving to become pre-service and early career professionals are able to present their 'selves' to prospective employers and peers in a more human and personal manner (Munday and Rowley 2016).

Our data also show that formal education in creative arts occurs across the career lifespan and that many people come to this field from other work. This presents a logical difficulty for higher education providers. In most instances, higher education is 
seen as a stepping-stone for a career where discipline-specific skills are developed in preparation for a working life. It follows that programs in art, music, theatre, writing and so on, mostly tend to focus on the arts practice or technical skill that is required. With or without a higher education degree, participants in this study were artistically capable across the career lifecycle. The role of higher education in their lives is therefore somewhat different from that expected by higher education institutions. Discipline competence is an assumed element of education, but more important (and mostly missing) are the elements that would enable these creative artists to have sustainable careers: to see 'within' the practice.

We suggest that creative arts programs be considered micro-businesses, reflecting the belief of creative and performing artists that what they do is meaningful work. Creative workers identify that their work has a purpose in which personal values are core to their artistic pursuits and are valued ahead of rewards such as a regular salary. The freedom to make independent choices, to contribute in a variety of creative and professional ways and to take charge of their own career management, empowers their growth.

Higher education could therefore usefully focus on different forms of discipline knowledge. This form of integrated professional training could include approaches to understanding community engagement, entrepreneurship, marketing, grant-getting strategies, collaborative practices, and cultural change. Moreover, it could ensure that students learn to recognise, articulate and further develop their skills and knowledge such that they understand the potential application in multiple settings within and beyond the arts. 
The role of creative arts in society, or community engagement, is highly problematic. Creative arts are central to specific cultural groups and work as knowledge holders and promulgators for that group. Creative artists belong to many different cultural groups and celebrate specific groups through their arts practice, but can also provide political commentary and dissent. So, it is not enough to simply teach 'arts practice' at university without situating that practice in relation to all aspects of culture and society. As we have seen, it seems important to creative workers that they have a strong personal identity as a creator, but we can see that this can identity can concern the relation a person has to the art form as well as the culture in which it resides. And then there is the problem of remunerating creative workers for their work. Because creative work is so central to culture, it is also missed as something that can be remunerated, perhaps because cultural heritage and change are not only the purview of creative artists but of all people. If a change were to made to the value of creative workers in society, perhaps higher education should include a cross-disciplinary approach so that lawyers, engineers, mathematicians, physiotherapists and others also develop an understanding of the utility of creative work for their own practice and situation.

Finally, we assert that creative artists need to be considered in a broader sense, as a non-homogenous group that demonstrates a wide range of cultural and education backgrounds. This non-homogeneity is part of the essence of creative work, as participants become commentators of culture and politics as well as provocateurs for society. And, they usually need to produce something that creates aesthetic pleasure for others. 
Creative artists spend a lifetime learning how to navigate careers within and beyond the arts: careers which demand an entrepreneurial and resilient mindset. Their sense of self - both being and becoming - needs an integrated form of higher education support that spans their different life stages. A combination of formal and experiential learning environments may assist in this pursuit. Traditional work-based learning solutions may not be appropriate for this particular group as work is distributed across multiple domains such that no single work environment could produce the range of artistic and business skills needed for the profession. However, higher education could span the gap through a reconsideration of the creative arts industry as predominantly the creation of micro-businesses. Taking this perspective, lived arts creation experience, formal discipline studies, and business thinking as core elements of education could significantly change the employability outcomes for creative arts graduates.

\section{References}

Alvesson, Mats, Karen Lee Ashcraft, and Robyn Thomas. 2008. "Identity Matters:

Reflections On The Construction Of Identity Scholarship In Organization Studies.” Organization 15, 5-28. doị: 10.1177/1350508407084426.

Ashforth, Blake E., Spencer H. Harrison, and Kevin G. Corley. 2008. "Identification in

Organizations: An Examination Of Four Fundamental Questions.” Journal of Management 34, 325-374. doi: 10.1177/0149206308316059.

Bennett, Dawn, Jane Coffey, Scott Fitzgerald, Peter Petocz, and Alistair Rainnie. 2014. "Beyond The Creative: Understanding The Intersection Of Specialist And Embedded Work For Creatives In Metropolitan Perth.” In Creative Work Beyond The Creative Industries: Innovation, Employment, And Education, edited by Greg 
Hearn, Ruth Bridgstock, Ben Goldsmith, and Jess Rodgers. Cheltenham: Edward Elgar Publishing.

Bennett, Dawn, Sarah Richardson, and Phillip Mackinnon. 2015. Enacting Strategies For Graduate Employability: How Universities Can Best Support Students To Develop Generic Skills. Sydney: Australian Government Office for Learning and Teaching.

Bennett, Dawn, and Sophie Hennekam. 2018. "Lifespan perspective theory and (classical) musicians' careers." In The classical music industry, edited by Chris Dromey and Julia Haferkorn. London: Routledge. https://www.crcpress.com/TheClassical-Music-Industry/Dromey-Haferkorn/p/book/9781138203693.

Bennett, Dawn, Anna Reid, and Jennifer Rowley. 2017. 'Student musicians' experiences of reflexivity during internships: Personal narratives and complex modalities.” International Journal of Music Education 35 (3), 460-475. doi: $10.1177 / 0255761416689843$.

Boud, David, Rozemary Keogh, and David Walker, ed. 1985. Reflection: Turning Experience Into Learning. London: Kogan Page.

Bridgstock, Ruth .2012. "Not a Dirty Word: Arts Entrepreneurship And Higher Education." Arts and Humanities in Higher Education 12 (2-3), 122-137. doi: $10.1177 / 1474022212465725$

Bruner, Edward M. (1986). "Ethnography as Narrative.” In The Anthropology Of Experience, edited by Victor W. Turner and Edward M. Bruner Chicago: University of Illinois Press. 
Comunian, Roberta, Abigail Gilmore, and Silvie Jacobi. 2015. "Higher Education And The Creative Economy: Creative Graduates, Knowledge Transfer And Regional Impact Debates.” Geography Compass 9 (7), 371-383. doi: 10.1111/gec3.v9.7.

Connelly, D. Jean and F. Michael Clandinin. 2004. Narrative Inquiry: Experience And Story In Qualitative Research. New York: Wiley.

Corden, Anne and Roy Sainsbury. 2006. Using Verbatim Quotations In Reporting Qualitative Social Research: Researchers'Views. York: University of York Social Policy Research Unit.

Cunningham, Stuart and Peter Higgs. 2010. What's Your Other Job? A Census Analysis Of Arts Employment In Australia. Melbourne: Australia Council for the Arts.

Dillon, Lisette. 2011. "Writing The Self : The Emergence Of A Dialogic Space." Narrative Inquiry, 21 (2), 213-237. doi: 10.1075/ni.21.2.03dil.

Fitzgerald, Scott, Alistair Rainnie, and Dawn Bennett. 2012. “Cultural Labour In Australia: Towards A Renewed Research Agenda." $26^{\text {th }}$ Australian and New Zealand Academy of Management Conference (no page). http://www.anzam.org/wp-content/uploads/pdf-manager/305_ANZAM-2012230.PDF.

Geonames https://www.geonames.org/ Accessed $7^{\text {th }}$ June, 2019.

Graduate Careers Council of Australia. 2015. Graduate Destinations 2015: A Report Of The Work And Study Outcomes Of Recent Higher Education Graduates. Melbourne: Graduate Careers Australia. of self in the creative and performing arts. Music Education Research, 21(4), 399-413. doi: 10.1080/14613808.2019.1632279. 
Gwozdek, Anne E., Emily C. Springfield, and Wendy E. Kerschbaum. 2013.

"Eportfolio: Developing A Catalyst For Critical Self-Assessment And Evaluation Of Learning Outcomes.” Journal of Allied Health, 42 (1), 11-17.

Hulme, Moira, and Julie Hughes. 2006. Patchwork E- Dialogues In The Professional Development Of New Teachers. In Technology Supported Learning And Teaching: A Staff Perspective, edited by John O’Donoghue. Hershey, PA: IGI Global. doi: 10.4018/978-1-59140-962-5.ch013.

Lawrence, Denis. 2006. Enhancing Self-Esteem In The Classroom. London: Paul Chapman Publishing.

Lebler, Don. 2014. Future Directions For Assessment In Assessment In Music Education: From Policy To Practice, edited by Don Lebler, Gemma Carey, and Scott. D. Harrison. New York: Springer.

Markus, Hazel and Paula Nurius. 1986. “Possible Selves.” American Psychologist, 41 (9), 954-969.

Munday, Jennifer, and Jennifer Rowley. 2017. Showing A Human And Professional Face To The World: An Eportfolio Design Strategy For A Sense Of Self. In Handbook Of Research On Humanizing The Distance Learning Experience, edited by Maria Northcote and Kevin P. Gosselin. Hershey, PA: IGI Global.

Munday, Jennifer, Jennifer Rowley, and Patsie Polly. 2017. “The Use Of Visual Image In Building Professional “Self” Identity." International Journal of ePortfolio 7 (1), $53-65$.

Peter Petocz, Anna Reid, and Dawn Bennett. 2014. The music workforce, cultural heritage and sustainability. International Journal of Cultural and Creative Industries 1(2), 4-16. 
http://www.ijcci.net/index.php?option=module\&lang=en\&task=pageinfo\&id=106 \&index $=4$.

Reid, Anna, Dawn Bennett, and Peter Petocz. 2016. Is Creative Work Sustainable? Understanding Identity, Motivation And Worth. Australian Journal of Career Development 25 (1), 33-41. doi: 10.1177/1038416216637089.

Reid, Anna and Ian Solomonides. 2007. “Design Students' Experience OfEngagement And Creativity." Art, Design and Communication in Higher Education 6 (1), 27 39. doi: 10.1386/adch.6.1.

Rowley, Jennifer and Dawn Bennett. 2016. "Eportfolios In Australian Higher Education Arts: Differences And Differentiations." International Journal of Education \& the Arts 17(19). http://www.ijea.org/v17n19/.

Rowley, Jennifer, Dawn Bennett, and Anna Reid. 2017. Leadership As A Core Creativity For Musician Identity. In Proceedings of The $21^{\text {st }}$ International Seminar Of The ISME Commission For The Education Of The Professional Musician, edited by Eddie Chong. Scotland: St Andrew's University.

Rowley, Jennifer and Jennifer Munday. 2014. “A Sense Of Self Through Reflective Thinking In Eportfolios.” International Journal of Humanities Social Sciences and Education 1(7), 78-85.

Ryan, Richard M., and Edward L. Deci. 2000. "Self-Determination Theory And The Facilitation Of Intrinsic Motivation, Social Development, And Well-Being.” American Psychologist January, 68-78.

Sabelis, Ida. 2010. Career Cultures: Rhythms Of Work From A Gender Perspective. In Geschlecht Und Innovation. Gender-Mainstreaming im TechnoWissenschaftsbetrieb, edited by Waltraud Ernst. Munster: LIT. 
Solomonides, Ian and Anna Reid. 2009. Understanding The Relationships Between Students' Identity And Engagement With Studies. In The Student Experience: Proceedings of the $32^{\text {nd }}$ HERDSA Annual Conference, edited by Helen Wozniak and Sonia Bartoluzzi. Sydney: HERDSA.

Solomonides, Ian. 2013. A Relational Model And Multi-Dimensional Model Of Student Engagement. In Student Engagement Handbook: Practice in Higher Education, edited by Elizabeth Dunne and Derfel Owen. Bingley: Emerald Group Publishing.

Throsby, David, and Anna Zednik. 2010. Do You Really Expect To Get Paid? An Economic Study Of Professional Artists In Australia. Melbourne: Australia Council for the Arts.

Vansteenkiste, Maarten and Kennon M. Sheldon. 2006. “There's Nothing More Practical Than A Good Theory: Integrating Motivational Interviewing And SelfDetermination Theory." British Journal of Clinical Psychology 45 (1), 63-82. doi: $10.1348 / 014466505 \times 34192$.

ZestFest http://zestfest.com.au/about/resources/ Accessed $7^{\text {th }}$ June, 2019. of self in the creative and performing arts. Music Education Research, 21(4), 399-413. doi: 10.1080/14613808.2019.1632279. 